\title{
Treatment allocation for the potential urgent patients in hospital emergency department to reduce length of stay - a simulation approach
}

\author{
Yu-Li Huang* \\ Mayo Clinic, Rochester, MN, USA
}

Received: June 15, 2015

Accepted: July 13, 2015

Online Published: July 28, 2015

DOI: $10.5430 / \mathrm{ijh} . v 1 \mathrm{n} 1 \mathrm{p} 1$

URL: http://dx.doi.org/10.5430/ijh.v1n1p1

\begin{abstract}
Extended waiting in the emergency room continues to be a recognized problem; to alleviate this many hospitals have adopted triage systems which classify patients based on their priority level and fast track processes for low acuity patients. This paper aims to reduce the length of stay in Emergency Department (ED) by allocating urgent patients in either the traditional treatment or the fast track route without compromising care for higher acuity patients. This study focuses on the five-priority level system and evaluates the concept using simulation and classification techniques. Literature has reported that priority three patients, whose conditions are initially not life threatening but may progress to a critical level, are the majority and normally encounter the longest wait. The simulation was built based on a difined ED patient flow considering factors such as patient arrival patterns, treatment times, and resource capacity. Analysis of Variance was conducted to determine the impact of each factor to the decision on level 3 patient allocation. A regression model was constructed to estimate the cycle time savings. Decision tree was used to further provide ED a general guideline on the allocation of level 3 patients. The study concludes that the fast track route as an option for level 3 patients is adequate if the fast track has higher or similar capacity as the traditional treatment route especially for the rural EDs where level 3 patients are identified $61 \%$ of time and required longer treatment. The patient cycle time saving estimated as much as three hours.
\end{abstract}

Key Words: Emergency department, Length of stay, Patient cycle time, Acuity level, Emergency severity index

\section{INTRODUCTION}

Many hospitals face the task of providing patients with quality care in terms of the length of stay with limited budgets and resources, especially in the Emergency Department (ED). Due to the increase in the number of ED visits nationwide, coupled with an increase in the average wait time, over the past decade and the continued registered nurse shortage, the adoption of more efficient practices has become increasingly important. ${ }^{[1,2]}$ With fewer than half of the hospitals in the U.S. meeting target triage time, for at least $90 \%$ of their pa- tients, long wait times in the ED are unavoidable. ${ }^{[3]}$ These extended wait times can have adverse affects on patients whose health conditions may deteriorate while awaiting treatment. ${ }^{[3-6]}$ ED providers are faced with higher stress due to the increased visits and wait times. They face a heavier workload with less than $16 \%$ of their time being spent on non-patient related activities such as completing and looking over patient paperwork and adequate staffing of emergency nurses continues to be a problem in many hospitals. ${ }^{[7-9]}$ The belief is that to alleviate the overcrowding in the $\mathrm{ED}$, one

*Correspondence: Yu-Li Huang, Ph.D.; Email: huang.yuli@mayo.edu; Address: Mayo Clinic, 200 First Street SW, Rochester, MN 55905, USA. 
of the key issues is determining how to allocate resources in such a way that patient safety is not compromised by wait times. This problem has been partially addressed by standardizing patient care with triage systems such as the Emergency Severity Index (ESI) and with the implementation of fast-track systems to treat less acute patients. The ESI triage nurses is responsible to assign patients an acuity level $1-5$, with 1 being the most acute and 5 being the least acute. The assignment criteria are summarized as the following. ${ }^{[10]}$ To meet criteria for level 1, a patient must require immediate attention to prevent the loss of life or limb. When deciding to classify patients as level 2 the most commonly used factors include age, vital signs, and need for timely treatment as well as the nurse's judgment from past experiences. Whereas the criteria used to determine level 3, level 4, and level 5 patients is based on resource utilization where a level 3 will require 2 or more resources, a level 4 will require one resource, and a level 5 requires 0 resources. One study investigating the actual number of resources, defined as required staff as well as tests required for diagnosis, consumed per acuity level showed that on average level 1 patients require 5 resources, level 2 patients 3.9 resources, level 3 patients 3.3 resources, level 4 patients 1.2 resources and level 5 patients 0.2 resources. ${ }^{[11]}$ Due to the variety of acuity levels and high demand in the lower acuity levels, the majority EDs have implemented a fast track system.

The goal of a fast track system in the ED is to reduce wait times by treating low acuity patients in a separate area and thereby freeing up space in the traditional treatment track area. ${ }^{[12]}$ Fast track systems are managed by and operate as an independent entity within the ED and may be run by nurses, physicians' assistants, physicians, or any combination of the aforementioned. ${ }^{[12]}$ Implementation of a fast track system has allowed many hospitals to reduce wait times and length of stay for low acuity patients while maintaining quality care under the stress of an increasing number of annual patients and relatively static resources. ${ }^{[13-16]}$ While the implementation of fast track systems have been shown to have positive effects in the ED, there is a large variation in how successful the implementation is depending upon operating conditions of pre-implementation. For example, in one study the hospital was already using an acuity level based triage system and once the fast track system was implemented it served $14.9 \%$ of ED entries and level 4 and 5 patients saw a decrease in wait time by 2 minutes, 24 to 22 minutes and 27 to 25 minuutes respectively; ${ }^{[16]}$ in another study the hospital was not using an acuity level based triage system and the overall patient wait time was decreased by 50\%, from 102 to 51 minutes. ${ }^{[14]}$ However, not all patients are reaping the benefits of these new programs; level 3 patients account for the largest patient group and experience the longest average stays in the ED. ${ }^{[11,17-19]}$ Some researchers proposed to split level 3 patients based on the variability where low variability would be sent through fast track system. ${ }^{[20]}$ However, the high-variability level 3 patients remained in high demand.

The focus of this study is to propose an emergency room model that reduces the length of stay in the ED for level 3 patients. Several EDs have two service routes for patients. The traditional route treats patients coming in with severe trauma who are normally classified as either level 1, 2 or 3 and is run mostly by more experienced physicians. The fast-track route treats non-urgent patients who are normally classified as level 4 and 5 and is usually run by nurse practitioners or physician assistants. The reduction in length of stay for level 3 patients can be achieved by allowing level 3 patients to be treated in either the traditional route or to be treated in the fast-track route. The main concept is to have level 3 patients seen by the first available provider from either route. Therefore, the decision on which treatment route to implement for level 3 patients is made by identifying resource availability and selecting the route that can treat the patient with minimal wait time. Although the concept is relatively intuitive and intends to assist the ED overcrowding issues for level 3 patients, there is not much work to support the ED practice to the direction.

\section{MeThod}

This study proposes to reduce the wait time for level 3 patients in an ED by determining the quickest route for level 3 patients without compromising care of higher acuity level patients using simulation and classification techniques. This routing system will not require additional infrastructure or personnel and will require only minimal changes to existing practices in triage. Simulation was selected for its relative ease of use, popularity, and accuracy in modeling EDs. Simulation has become a widely accepted and useful tool in healthcare settings because of the capability to make decisions from limited data and the capability to analyze multiple scenarios in a relatively short period of time. Several simulation approaches have been accepted as capable of providing a usable ED model; SIMUL8 was used to identify areas for improvement in terms of length of stay in a community hospital, ${ }^{[21]}$ object-oriented programming was used to develop an interactive decision support system ${ }^{[22]}$ and ARENA 10.0 is used to model how different patient arrival patterns influence an EDs ability to treat patients after a terror disaster event. ${ }^{[23]}$ The simulation was done in Matlab. The purpose of simulation is to model ED patient flow and help allocate the level 3 patients. The decision on allocating level 3 patients in either the traditional or the fast track is based on parameters 
such as patient arrival patterns, patient treatment times, and treatment capacity using decision tree classification.

\subsection{Emergency department patient flow}

The simulation explored one alternative by modifying patient routing for level 3 patients in an ED with existing infrastructure for a fast track and which utilizes the ESI triage method to determine patient levels (see Figure 1).

In the model all patients enter through a single queue in the waiting room, regardless of method of arrival (walk-in, ambulance, airlift). The queue is a first in first out queue that takes into account patient priority. When a level 1 patient arrives they bypass registration and triage and are taken to a treatment room immediately. All other patients are processed through registration and then remain in the waiting room for triage. When a triage room becomes available the patient is taken back and the determination of whether the patient belongs in the fast track queue or the traditional treatment queue is made. In the existing situation all level 2 and level 3 patients join the traditional treatment queue. The traditional treatment queue is a first in first out queue with patient priority taken into account. Each time when a level 2 patient joins the queue, level 3 patients are pushed farther down the queue. Within a level, patients are seen in order of arrival time. All level 4 and level 5 patients join the fast track queue. The fast track queue is strictly a first in first out queue and does not take into account whether a patient is a level 4 or level 5 .

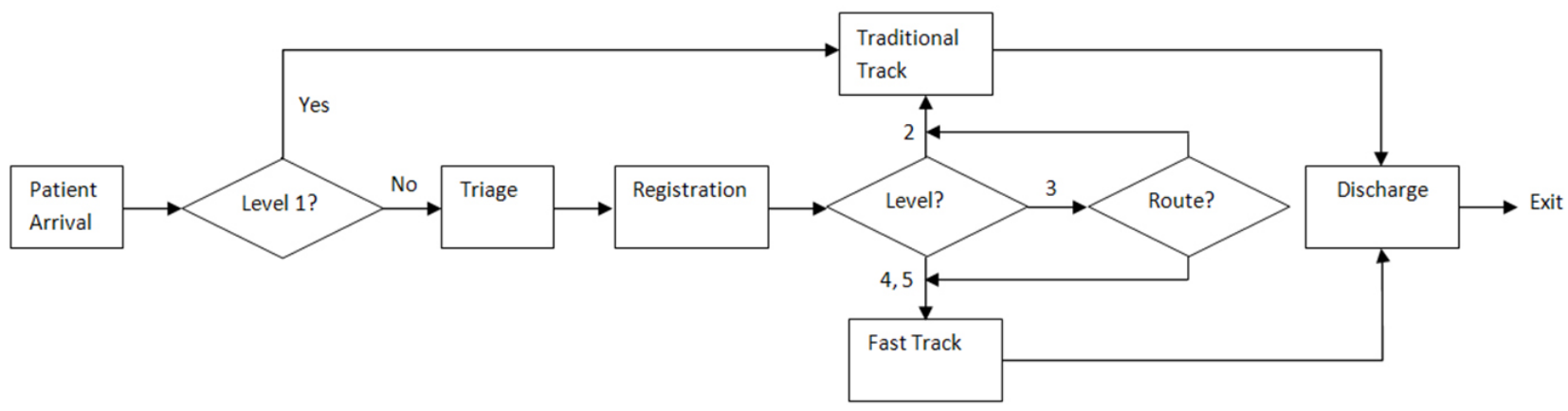

Figure 1. The general patient flow with options for level 3 patients used for simulation modeling

In the proposed model, level 3 patients are not assigned to either the traditional treatment queue or the fast track queue, but instead have their place held in both and are treated by whichever system has the shortest wait time. All level 1 and 2 patients are still treated in the traditional treatment route and level 4 and 5 patients are still treated in the fast track treatment route. In both scenarios all patients remain in the waiting room regardless of which queue they are in. When a traditional treatment room or fast track room becomes available the patient is taken back for treatment. Treatment times are defined as the time from when a patient begins to occupy a room until they exit the room. Upon completion of treatment, patients exit the model regardless of outcome (discharge, admission, morgue...etc.). The consequent activities after completion of treatment from ED such as waiting for transportation to operating room or ICU are not included as a part of cycle time, which the ED exam rooms are assumed to be available right after the treatment is completed.

\subsection{Simulation modeling and assumptions}

For the simulation model to be more realistic, assumptions for the key parameters are defined based on literature findings; see Table 1 and Table 2. Patient inter-arrival times were determined based on McCarthy et al..$^{[24]}$ and were taken in

Published by Sciedu Press percentages from the study and included into three eight-hour time blocks, midnight to 8:00 am, 8:00 am to 4:00 pm, and 4:00 pm to midnight. During the eight-hour blocks patient inter-arrival times are random. The frequency of arrival of different acuity levels (see Table 1) is extracted from the articles by Khurma, Bacioiu, and Pasek ${ }^{[25]}$ and Wiler et al. ${ }^{[19]}$ The first article represents the high level $(\mathrm{H})$ frequency of patient arrival that is based on urban ED which services over 57,000 patients annually. The latter one represents the low level (L) frequency of patient arrival which is a suburban community hospital that served over 40,000 patients during the one year study period. The number of rooms available for triage, treatment, and fast track (see Table 2) are based on the number of teams of doctors and nurses available in the ED, for example if there is only one doctor and one nurse available the number of rooms where a patient can be continuously treated is one, if there are two doctors available the number of patients able to be continuously treated is two, and so on. Registration and triage times (see Table 1) are held constant regardless of acuity level and are based on the findings from Badri and Hollingsworth. ${ }^{[26]}$ Registration time follows the Triangular distribution with minimum of 3 minutes, median of 5 minutes, and maximum of 7 minutes. 
Triage time follows the Poisson distribution with mean of 6 minutes. Treatment times (see Table 1) are based on the article by McCarthy et al. ${ }^{[24]}$ Where the median values are taken from the study representing the high level $(\mathrm{H})$ from a hospital that serves over 39,000 patients annually and the low level (L) from a hospital that serves almost 35,000 patients annually. A triangular distribution is used to demonstrate treatment time and a 20-minute deviation is added and subtracted to form the maximum and minimum values respectively.

Table 1. Parameters assumed for patient arrivals, registration, triage, and treatment time

\begin{tabular}{|c|c|c|c|c|c|c|}
\hline \multirow{2}{*}{ Patient Level } & \multicolumn{2}{|c|}{ Patient Arrival Frequency } & \multirow{2}{*}{ Registration (min) } & \multirow{2}{*}{ Triage (min) } & \multicolumn{2}{|c|}{ Treatment Time (min) } \\
\hline & $\mathbf{H}$ & $\mathbf{L}$ & & & $\mathbf{H}$ & $\mathbf{L}$ \\
\hline 1 & $1 \%$ & $0.2 \%$ & & & Tria $(79,99,119)$ & Tria $(14,34,54)$ \\
\hline 2 & $7 \%$ & $5.5 \%$ & & & Tria $(229,249,269)$ & Tria $(214,234,254)$ \\
\hline 3 & $33 \%$ & $60.6 \%$ & Tria $(3,5,7)$ & Poisson (6) & Tria $(239,259,279)$ & Tria $(180,200,220)$ \\
\hline 4 & $43 \%$ & $31.6 \%$ & & & Tria $(79,95,115)$ & Tria $(79,99,119)$ \\
\hline
\end{tabular}

Table 2. Parameters assumed for inter-arrival time and capacity

\begin{tabular}{lllllll}
\hline & \multicolumn{2}{l}{ Inter-arrival Time (\%) } & \multicolumn{3}{c}{ Rooms Available } \\
\cline { 2 - 7 } & 12am & 8am- & 4pm- & Triage & Treatment & $\begin{array}{l}\text { Fast } \\
\text { Track }\end{array}$ \\
\hline H & \multirow{2}{*}{17} & \multirow{2}{*}{44} & 39 & 3 & 2 & 2 \\
L & & & & 1 & 1 & 1 \\
\hline
\end{tabular}

During the development of the model several assumptions were made for simplification and clarification. The model assumes that the hospital is already using a 5-tier acuity system, namely the ESI method; however, other 5-level triage systems may be easily adjusted. The model also assumes that the hospital has existing infrastructure and adequate staffing for a fast track to be open 24 hours per day. In addition, the simulation was done in such a way that patients are assumed to be undergoing continuous treatment while they are occupying a triage, treatment, or fast-track room. Another assumption of the model is that the number of staffing teams is constant throughout the day and the testing resources are sufficient to accommodate all patients in treatment so there is no additional wait time for these resources. The model incorporates two levels for patient acuity level arrivals, available rooms, and treatment times. Each grouping of levels, high $(\mathrm{H})$ or low $(\mathrm{L})$, represents different hospitals and the different number of resources and patient acuity level distributions they may encounter.

\subsection{Simulation runs and analysis}

Two treatment routes are commonly used for current ER practice. One is the traditional treatment route and the other is the fast track route. Two different sets of simulation were run. The first simulation represents the current ER practice of all level 3 patients going through the traditional treatment route and the second simulation represents the proposed method of providing level 3 patients options to be sent through either the traditional or the fast track route, whichever becomes available first. Each simulation consists of two levels of patient arrival frequency (PAF), two levels of treatment time for every patient acuity level (Level $\mathrm{i}$, where $\mathrm{i}=1,2,3$, 4,5 ) and two levels of capacity for triage (TC), traditional treatment route capacity (TTC) and fast track route capacity (FTC). There are nine two-level parameters, for a total of $512(2 \times 2 \times 2 \times 2 \times 2 \times 2 \times 2 \times 2 \times 2)$ scenarios, investigated for each simulation which sums up to a total of 1,024 data points. Each data point is the average of 50 replications. The first analysis is to understand if there is any difference between two simulations (S), the current ED practice versus providing route options for level 3 patients, in terms of the average cycle time or the time patients spent in ED. An Analysis of Variance (ANOVA) with all parameters is conducted. The hypothesis is $\mathrm{H}_{0}$ : there is no difference between the two simulations and $\mathrm{H}_{1}$ : there is a significant difference between the two simulations. Table 3 indicates that the two simulations are significantly different at the level of 0.05 . Among these parameters, the patient arrival frequency, level 3 treatment time, triage capacity, traditional treatment capacity, and fast track capacity significantly impact the patient cycle time in ED. The analysis indicates that the cycle time savings in ED is 13 minutes on average. The cycle time savings seems to be very small compared to a more than 4 hour ED visit.

The small improvement on the proposed method in the average cycle time indicates that not all scenarios are benefited from having options for level 3 patients in terms of ED cycle time reduction. Hence, the second analysis is to find out in which scenarios the proposed method can actually reduce the cycle time. Decision trees are popular in the healthcare setting for their relative efficiency, computational ease, ease 
of interpretation, and visual appeal in terms of display. [27-29] A decision tree method is used to identify when the proposed method or the current ED practice should be used. The decision is generated using $\mathrm{R}$ software. The tree determined to use four parameters to classify scenarios for level 3 patients into either the traditional treatment route $(\mathrm{T})$ or the fast track route $(\mathrm{F})$; see Figure 2 . The four key parameters are: FTC, traditional TTC, PAF, and level 3 patient treatment time (Level 3).

Table 3. ANOVA results for patient cycle time in ED

\begin{tabular}{llllll}
\hline Source & DF & SS & MS & F & $\boldsymbol{p}$ \\
\hline S & 1 & 42914 & 42914 & 12.92 & $<.0001$ \\
PAF & 1 & 1017184 & 1017184 & 306.29 & $<.0001$ \\
Level 1 & 1 & 18 & 18 & 0.01 & .941 \\
Level 2 & 1 & 302 & 302 & 0.09 & .763 \\
Level 3 & 1 & 3149700 & 3149700 & 948.42 & $<.0001$ \\
Level 4 & 1 & 26 & 26 & 0.01 & .929 \\
Level 5 & 1 & 4 & 4 & 0.00 & .974 \\
TC & 1 & 60727 & 60727 & 18.29 & $<.0001$ \\
TTC & 1 & 1154964 & 1154964 & 347.78 & $<.0001$ \\
FTC & 1 & 40768 & 40768 & 12.28 & $<.0001$ \\
Error & 1013 & 3364164 & 3321 & & \\
Total & 1023 & 8830772 & & & \\
\hline
\end{tabular}

Note. $\mathrm{S}=57.63, \mathrm{R}^{2}=61.9 \%$

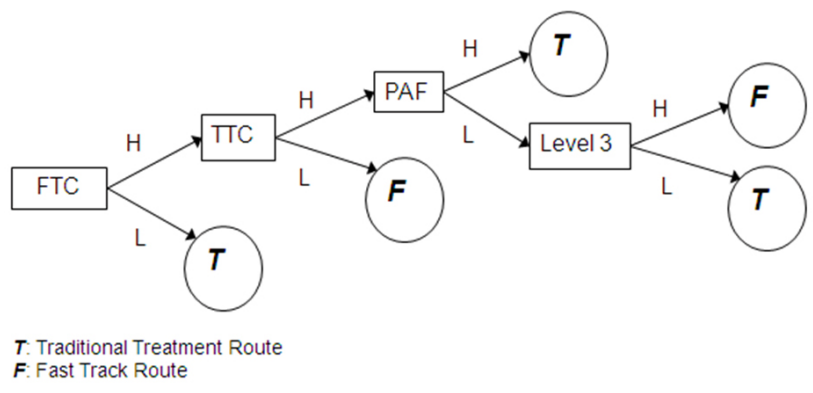

Figure 2. The decision tree results

The first split occurs with the fast track capacity, when fast track capacity is low the traditional treatment route is preferable due to the high volume of level 4 and 5 patients. The second split occurs at the capacity of traditional treatment route. When the fast track capacity is high and the traditional capacity is low, the results indicate that the fast track route is preferable. This is a result of space being limited in the traditional route and having more room to treat patients in the fast track route. The next split is based on the patient arrival frequency. When the fast track capacity is high, the traditional capacity is high and the patient arrival frequency is high (urban area), the traditional treatment route should be selected. This again is a result of the large proportion of level 4 and 5 patients that the fast track route services when the capacity of both routes are the same. The final split occurs at level 3 patient treatment times. Given the fast track capacity is high, the traditional capacity is high and the patient arrival frequency is low (suburban area), when treatment times are high the fast track route is preferable since each level 3 patient requires more time, the low patient arrival frequency allows the fast track route to have lighter load on level 4 and 5 patients. On the other hand, when the level 3 patient treatment times are low the traditional route is preferable due to the similarity of capacity from both routes. Simulating a ED patient flow by the current ED practice and the proposed method that provides an options for level 3 patients allows us to understand the factors that impact patient flow and determine which method is the most appropriate under a given ED conditions.

\section{Results}

ANOVA result indicates that providing level 3 patients with an option of going through the fast track route does significantly reduce patient cycle time during ER visit. The decision tree analysis further provides ED general guideline on deciding whether the fast track option for level 3 patients is adequate for cycle time improvement. In general, an ED department will adopt the fast track option approach when the fast track route has higher capacity or more available medical staff for the hospitals in any area. In addition, when the capacities of the traditional treatment route and the fast track route are the same, the rural hospital with limited advanced technical resources (longer treatment time) should provide the fast track option for level 3 patients to reduce the overall stay in ED. From a total of 512 scenarios where level 3 patients were provided the option of going through the fast track, the finding was that due to the high percentage, more than $90 \%$, of level 3, 4, and 5 visits, the option of using fast track as an alternative route for level 3 patients is limited. There are only 104 out of 512 scenarios using the fast track option and have cycle time savings of more than 10 minutes; see Table 4. The scenarios consist of PAF, level 1 patient treatment time, level 2 patient treatment time, level 3 patient treatment time (Level 3), level 4 patient treatment time, level 5 patient treatment time, TC, TTC, and FTC where a checkmarked $(\sqrt{ })$ means the level occurs. For example, for cycle time saving of 65-70, PAF is only at $\mathrm{L}$ level, Level 1 can be at both levels, Level 2 is only at $\mathrm{H}$ level, Level 3 is only at $\mathrm{L}$ level, Level 4 is only at $\mathrm{H}$ level, Level 5 can be at both levels, TC is only at L, TTC is only at L, and FTC is only at $\mathrm{H}$ level. Three scenarios at this cycle time saving are LHHLHHLLH, LHHLHLLLH, and LLHLHHLLH.

Table 4 concludes the cycle time savings from the scenarios that provide the fast track option for level 3 patients. All 
scenarios representing cycle time savings have one common characteristic of low patient arrival frequency, which leads us to believe providing the fast track option for level 3 patients will benefit the most for ED in suburban areas. For scenarios where the cycle time savings are 55 minutes ( $\sim$ one hour) and above, the common characteristics are patient arrival frequency is at low, traditional treatment route capacity is at low and fast track capacity is at high. The interpretation is that when fast track capacity is higher than traditional treatment route for rural hospital ED, providing a fast track option for level 3 patients will reduce the average patient cycle time by at least an hour. Among these cases, factoring in higher or longer level 3 treatment times, the cycle time savings will be at least 170 minutes ( $\sim 3$ hours). For these scenarios where the cycle time savings is less than 30 minutes, besides the low patient arrival frequency and high on level 3 treatment times, both capacities for traditional treatment route and fast track route are either at high or low. When both capacities are at high the cycle time savings is 15 minutes or less and when both are at low the savings is more but less than 30 minutes. The scenario analysis has identified four significant factors what impact the cycle time saving. A predictive statistical model will be useful for an ED to decide if providing a fast track option for level 3 patients is worthwhile in terms of the cycle time savings. A simple linear regression model is built for the time savings prediction; see Table 5. High level for each factor is chosen to be the reference level.

Table 4. The factors associated with each cycle time saving that uses the fast track option for level 3 patients

\begin{tabular}{|c|c|c|c|c|c|c|c|c|c|c|c|c|c|c|c|c|c|c|c|}
\hline \multirow{2}{*}{$\begin{array}{l}\text { Cycle Time } \\
\text { Saving (min) }\end{array}$} & \multirow{2}{*}{$\begin{array}{l}\text { \# of } \\
\text { scenarios }\end{array}$} & \multicolumn{2}{|c|}{ PAF } & \multicolumn{2}{|c|}{ Level 1} & \multicolumn{2}{|c|}{ Level 2} & \multicolumn{2}{|c|}{ Level 3} & \multicolumn{2}{|c|}{ Level 4} & \multicolumn{2}{|c|}{ Level 5} & \multicolumn{2}{|c|}{ TC } & \multicolumn{2}{|c|}{ TTC } & \multicolumn{2}{|c|}{ FTC } \\
\hline & & $\mathbf{L}$ & $\mathbf{H}$ & $\mathbf{L}$ & H & $\mathbf{L}$ & H & $\mathbf{L}$ & H & $\mathbf{L}$ & H & $\mathbf{L}$ & $\mathbf{H}$ & $\mathbf{L}$ & H & $\mathbf{L}$ & $\mathbf{H}$ & $\mathbf{L}$ & $\mathbf{H}$ \\
\hline $10-15$ & 8 & $\sqrt{ }$ & & $\sqrt{ }$ & $\sqrt{ }$ & $\sqrt{ }$ & $\sqrt{ }$ & & $\sqrt{ }$ & $\sqrt{ }$ & $\sqrt{ }$ & $\sqrt{ }$ & $\sqrt{ }$ & $\sqrt{ }$ & & & $\sqrt{ }$ & & $\sqrt{ }$ \\
\hline $15-20$ & 23 & $\sqrt{ }$ & & $\sqrt{ }$ & $\sqrt{ }$ & $\sqrt{ }$ & $\sqrt{ }$ & & $\sqrt{ }$ & $\sqrt{ }$ & $\sqrt{ }$ & $\sqrt{ }$ & $\sqrt{ }$ & $\sqrt{ }$ & $\sqrt{ }$ & $\sqrt{ }$ & & $\sqrt{ }$ & \\
\hline $20-25$ & 9 & $\sqrt{ }$ & & $\sqrt{ }$ & $\sqrt{ }$ & $\sqrt{ }$ & $\sqrt{ }$ & & $\sqrt{ }$ & $\sqrt{ }$ & $\sqrt{ }$ & $\sqrt{ }$ & $\sqrt{ }$ & $\sqrt{ }$ & $\sqrt{ }$ & $\sqrt{ }$ & & & \\
\hline $55-60$ & 13 & $\sqrt{ }$ & & $\sqrt{ }$ & $\sqrt{ }$ & $\sqrt{ }$ & $\sqrt{ }$ & $\sqrt{ }$ & & $\sqrt{ }$ & $\sqrt{ }$ & $\sqrt{ }$ & $\sqrt{ }$ & $\sqrt{ }$ & $\sqrt{ }$ & $\sqrt{ }$ & & & $\sqrt{ }$ \\
\hline $60-65$ & 16 & $\sqrt{ }$ & & $\sqrt{ }$ & $\sqrt{ }$ & $\sqrt{ }$ & $\sqrt{ }$ & $\sqrt{ }$ & & $\sqrt{ }$ & $\sqrt{ }$ & $\sqrt{ }$ & $\sqrt{ }$ & $\sqrt{ }$ & $\sqrt{ }$ & $\sqrt{ }$ & & & $\sqrt{ }$ \\
\hline $65-70$ & 3 & $\sqrt{ }$ & & $\sqrt{ }$ & $\sqrt{ }$ & & $\sqrt{ }$ & $\sqrt{ }$ & & & $\sqrt{ }$ & $\sqrt{ }$ & $\sqrt{ }$ & $\sqrt{ }$ & & $\sqrt{ }$ & & & $\sqrt{ }$ \\
\hline $170-175$ & 3 & $\sqrt{ }$ & & $\sqrt{ }$ & $\sqrt{ }$ & $\sqrt{ }$ & & & $\sqrt{ }$ & $\sqrt{ }$ & & $\sqrt{ }$ & $\sqrt{ }$ & & $\sqrt{ }$ & $\sqrt{ }$ & & & $\sqrt{ }$ \\
\hline $175-180$ & 9 & $\sqrt{ }$ & & $\sqrt{ }$ & $\sqrt{ }$ & $\sqrt{ }$ & $\sqrt{ }$ & & $\sqrt{ }$ & $\sqrt{ }$ & $\sqrt{ }$ & $\sqrt{ }$ & $\sqrt{ }$ & $\sqrt{ }$ & $\sqrt{ }$ & $\sqrt{ }$ & & & $\sqrt{ }$ \\
\hline $180-185$ & 14 & $\sqrt{ }$ & & $\sqrt{ }$ & $\sqrt{ }$ & $\sqrt{ }$ & $\sqrt{ }$ & & $\sqrt{ }$ & $\sqrt{ }$ & $\sqrt{ }$ & $\sqrt{ }$ & $\sqrt{ }$ & $\sqrt{ }$ & $\sqrt{ }$ & $\sqrt{ }$ & & & $\sqrt{ }$ \\
\hline $185-190$ & 5 & $\sqrt{ }$ & & $\sqrt{ }$ & $\sqrt{ }$ & $\sqrt{ }$ & $\sqrt{ }$ & & $\sqrt{ }$ & & $\sqrt{ }$ & $\sqrt{ }$ & $\sqrt{ }$ & $\sqrt{ }$ & & $\sqrt{ }$ & & & $\sqrt{ }$ \\
\hline $190-195$ & 1 & $\sqrt{ }$ & & & $\sqrt{ }$ & & $\sqrt{ }$ & & $\sqrt{ }$ & & $\sqrt{ }$ & & $\sqrt{ }$ & $\sqrt{ }$ & & $\sqrt{ }$ & & & $\sqrt{ }$ \\
\hline
\end{tabular}

Table 5. Regression analysis results with high level as reference

\begin{tabular}{lllll}
\hline & Coefficients & Error & $\boldsymbol{t}$ value & $\boldsymbol{p}$ \\
\hline Intercept & -57.56 & 6.83 & -8.43 & $<.0001$ \\
PAF (low) & 92.83 & 5.85 & 15.88 & $<.0001$ \\
Level 3 (low) & -38.92 & 4.41 & -8.83 & $<.0001$ \\
TTC (low) & 87.60 & 5.33 & 16.45 & $<.0001$ \\
FTC (low) & -81.53 & 5.27 & -15.49 & $<.0001$ \\
\hline
\end{tabular}

The estimated cycle time savings that are based on our data can easily be modeled by the equation of: Cycle time savings $=-57.56+92.83$ RAF (low) -38.92 Level 3 (low) +87.6 TTC (low) -81.53 FTC (low). When the estimated cycle time savings is less than zero, this simply means there is no savings at all. For example on the case with high cycle time savings where RAF is low, Level 3 is high, TTC is low and FTC is high, the estimated savings is $-57.56+92.83+$ $87.6=122.87$, which is about 2 hours. This model again provides cycle time savings estimation for one to determine if the alternative of having the fast track option for level 3 patients is a potential solution for reducing ED stay.

\section{Conclusions}

This research aims to reduce the length of stay for level 3 patients in an ED by providing an alternative treatment option via the fast track route to quickly assess by the first available treatment option. The evalution of this alternative treatment option is determined by the results from simulations based on a defined ED patient flow and parameters such as patient arrival frequency, length of treatment time, and treatment capacity. Level 3 patients are considered urgent and require more resources compared to level 4 and 5 due to the uncertainty of patient conditions. They also required more experienced medical staff for more accurate diagnosis via the traditional treatment route. Due to the high percentage of ED patients who are classified as level 3 (30\% to 60\%), overcrowding becomes inevitable which generates a long ED stay. Rather than waiting for the traditional treatment route by more experienced medical teams, level 3 patients should 
be seen by the first available medical team even through the fast track route. The results indicate the significant reduction on the length of stay in ED is estimated to be as much as three hours given the modeling assumptions. The results provide a general guideline, especially for the rural hospital EDs, to determine if the fast track option will improve the efficiency of patient flow in overall cycle time based on their current ED condition such as resource availability in level 3 patient treatment time, fast track, and traditional treatment route capacities. The decision tree study concludes that a rural ED department will use the fast track route as an option for level 3 patients only if the fast track route has higher capacity or more available medical staff and when the capacities of the traditional treatment route and the fast track route are the same, the hospital ED with a longer level 3 patient treatment time. As for the urban hospital ED, the current practice in which level 3 patients go through the traditional treatment route is the appropriate method. The paper also presents a predictive model that help ED managers make a decision on whether the fast track option could actually save the length of stay in ED and estimate the savings. Limitations for generalization are the assumptions made regarding the representation of urban and suburban hospital EDs in terms of patient arrival, the fast track route work hours and the difference in treatments between the traditional treatment route, and the fast track route. These are potential future research. Implementation to provide feasibility issues and outcomes remains to be seen. Consequently, the impact of timely discharge of inpatients, promoting OR efficiency, having weekend staffing, ED admission process and ambulance diversion can be also discovered for future research. In summary, the paper demonstrates an alternative concept that will reduce patient length of stay in a hospital ED.

\section{REFERENCES}

[1] Wilper AP, Woolhandler S, Lasser KE, et al. Waits to see an emergency department physician: U.S. trends and predictors, 19972004. Health Affairs. 2008; 27(2): 84-95. PMid: 18198184. http: //dx.doi.org/10.1377/hlthaff.27.2.w84

[2] Herring A, Wilper A, Himmelstein DU, et al. Increasing length of stay among adult visits to U.S. emergency departments, 2001-2005. Academic Emergency Medicine. 2009; 16(7): 609-616. PMid: 19538503. http://dx.doi.org/10.1111/j.1553-2712.2009.00428.x

[3] Horwitz LI, Green J, Bradley EH. US emergency department performance on wait time and length of visit. Annals of Emergency Medicine. 2010; 55(2): 133-141. PMid: 19796844. http://dx.d oi.org/10.1016/j.annemergmed.2009.07.023

[4] Liew D, Liew D, Kennedy MP. Emergency department length of stay independently predicts excess inpatient length of stay. The Medical Journal of Australia. 2003; 179(10): 524-526. PMid: 14609414.

[5] Sprivulis PC, Da Silva JA, Jacobs IG, et al. The association between hospital overcrowding and mortality among patients admitted via western Australian emergency departments. The Medical Journal of Australia. 2006; 184(5): 208-212. PMid: 16515429.

[6] Andersson AK, Omberg M, Svedlund M. Triage in the emergency department - a qualitative study of the factors which nurses consider when making decisions. Nursing in Critical Care. 2006; 11(3): 136145. PMid: 16719019. http://dx.doi.org/10.1111/j.1362-1 $017.2006 .00162 . \mathrm{x}$

[7] Anderson CK, Zaric GS, Dreyer JF, et al. Physician workload and the Canadian Emergency Department Triage and Acuity Scale: the Predictors of Workload in the Emergency Room (POWER) Study. Canadian Journal of Emergency Medicine. 2009; 11(4): 321-329.

[8] Hoi SY, Ismail N, Ong LC, et al. Determining nurse staffing needs: the workload intensity measurement system. Journal of Nursing Management. 2010; 18(1): 44-53. PMid: 20465728. http://dx.doi.o $\mathrm{rg} / 10.1111 / \mathrm{j} .1365-2834.2009 .01045 . \mathrm{x}$

[9] Liu LF, Lee S, Chia PF, et al. Exploring the Association Between Nurse Workload and Nurse-Sensitive Patient Safety Outcome Indicators. The Journal of Nursing Research. 2012; 20(4): 300-309.
PMid: 23154441. http://dx.doi.org/10.1097/jnr.0b013e3 182736363

[10] Garbez R, Carrieri-Kohlman MV, Stotts N, et al. Factors Influencing Patient Assignment to Level 2 and Level 3 Within the 5-Level ESI Triage System. Journal of Emergency Nursing. 2011; 37(6): 526532. PMid: 22074652. http://dx.doi.org/10.1016/j.jen.2 010.07 .010

[11] Tanabe P, Gimbel R, Yarnold PR, et al. The Emergency Severity Index (version 3) 5-level triage system scores predict ED resource consumption. Journal of Emergency Nursing. 2004; 30(1): 22-29. PMid: 14765078. http://dx.doi.org/10.1016/j.jen. 2003. 11.004

[12] Taylor D, Bennett D, Cameron P. A paradigm shift in the nature of care provision in emergency departments. Emergency Medicine Journal. 2004; 21(6): 681-684. PMid: 15496693. http://dx.doi .org/10.1136/emj. 2004.017640

[13] O’Brien D, Williams A, Blondell K, et al. Impact of streaming "fast track" emergency department patients. Australian Health Review. 2006; 30(4): 525-532. PMid: 17073548. http://dx.doi .org/10. 1071/AH060525

[14] Sanchez M, Smally AJ, Grant RJ, et al. Effects of a fast-track area on emergency department performance. The Journal of Emergency Medicine. 2006; 31(1): 117-120. PMid: 16798173. http: //dx.doi.org/10.1016/j.jemermed.2005.08.019

[15] Considine J, Kropman M, Kelly E, et al. Effect of emergency department fast track on emergency department length of stay: a casecontrol study. Emergency Medicine Journal. 2008; 25(12): 815-819. PMid: 19033498. http://dx.doi.org/10.1136/emj.2008.05 7919

[16] Kwa P, Blake D. Fast track: Has it changed patient care in the emergency department? Emergency medicine Australasia. 2008; 20(1): 10-15. PMid: 17999686. http://dx.doi.org/10.1111/j.174 2-6723.2007.01021.x

[17] van der Wulp I, Schrijvers AJ, van Stel HF. Predicting admission and mortality with the Emergency Severity Index and the Manchester Triage System: a retrospective observational study. Emer- 
gency Medicine Journal. 2009; 26(7): 506-509. PMid: 19546272. http://dx.doi.org/10.1136/emj . 2008.063768

[18] Storm-Versloot MN, Ubbink DT, Kappelhof J, et al. Comparison of an Informally Structured Triage System, the Emergency Severity Index, and the Manchester Triage System to Distinguish Patient Priority in the Emergency Department. Academic Emergency Medicine. 2011; 18(8): 822-829. PMid: 21843217. http: //dx.doi.org/10.1111/j.1553-2712.2011.01122.x

[19] Wiler JL, Poirier RF, Farley H, et al. Emergency Severity Index Triage System Correlation with Emergency Department Evaluation and Management Billing Codes and Total Professional Charges. Academic Emergency Medicine. 2011; 18(11): 1161-1166. PMid: 22092897. http://dx.doi.org/10.1111/j.1553-2712.2011 $.01203 . x$

[20] Arya R, Wei G, McCoy JV, et al. Decreasing length of stay in the emergency department with a split emergency severity index 3 patient flow model. Academic Emergency Medicine. 2013; 20(11): 11711179. PMid: 24238321. http://dx.doi.org/10.1111/acem.12 249

[21] Wang J, Li J, Tussey K, et al. Reducing Length of Stay in Emergency Department: A Simulation Study at a Community Hospital. IEEE Transactions on Systems, Man, and Cybernetics. 2012; 42(6): 1314 1322. http://dx.doi.org/10.1109/TSMCA . 2012.2210204

[22] Abo-Hamad W, Arisha A. Simulation-based framework to improve patient experience in an emergency department. European Journal of Operational Research. 2013; 224(1): 154-166. http://dx.doi.o $\mathrm{rg} / 10.1016 / \mathrm{j}$. ejor.2012.07.028
[23] Joshi AJ, Rys MJ. Study on the effect of different arrival patterns on an emergency department's capacity using discrete event simulation. International Journal of Industrial Engineering. 2011; 18(1): 40-50.

[24] McCarthy ML, Zeger SL, Ding R, et al. Crowding delays treatment and lengthens emergency department length of stay, even among high-acuity patients. Annals of Emergency Medicine. 2009; 54(4): 492-503. PMid: 19423188. http://dx.doi.org/10.1016/j.a nnemergmed.2009.03.006

[25] Khurma N, Bacioiu GM, Pasek ZJ. Simulation-based verification of lean improvement for emergency room process. Winter Simulation Conference. 2008; 2008: 1490-1499. http://dx.doi.org/10.11 09/wsc. 2008.4736229

[26] Badri MA, Hollingsworth J. A simulation model for scheduling in the emergency room. International Journal of Operations \& Production Management. 1993; 13(3): 13-24. http://dx.doi.org/10.1108 /01443579310025989

[27] Li L, Zhang X. Study of data mining algorithm based on decision tree. Computer Design and Applications (ICCDA) 2010 International Conference. 2010.

[28] Huang Y, Marcak J. Radiology scheduling with consideration of patient characteristics to improve patient access to care and medical resource utilization. Health Systems. 2013; 2(2): 93-102. http: //dx.doi.org/10.1057/hs.2013.1

[29] Hu R. Medical Data Mining Based on Decision Tree Algorithm. Computer and Information Science. 2011; 4(5): 14-19. http: //dx.doi.org/10.5539/cis.v4n5p14 